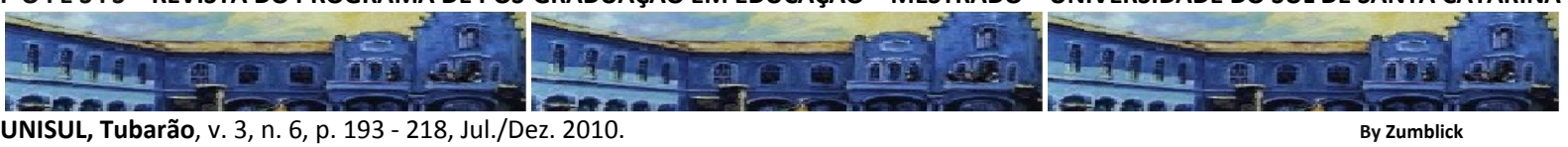

\title{
DO LOGOS ESTÉTICO AO LOGOS CULTURAL: IMPLICAÇÕES ÉTICAS DA FENOMENOLOGIA DO CORPO PRÓPRIO ${ }^{1}$
}

\author{
Márcio Junglos ${ }^{2}$
}

\section{RESUMO:}

Este trabalho levantará questões concernentes a uma ética fenomenológica. Para isto, procuraremos encontrar subsídios através da passagem do logos do mundo estético para o logos do mundo cultural, em Merleau-Ponty. Um fio condutor será determinado por este filósofo, com o intento de entender a natureza da vida no mundo. Este fio condutor é chamado de presença originária que, por sua vez, pode ser identificado tanto no logos estético como no logos cultural. Merleau-Ponty faz uma profunda análise dos estudos levantados por Husserl, especialmente o Husserl mais tardio, no qual encontramos a descoberta de uma fenomenologia da vida. Por meio da descoberta do corporeflexionante, Merleau-Ponty celebra a encarnação da fenomenologia da vida levantada por Husserl. Estes dois filósofos conferem uma profunda ênfase em relação a nossa atitude através da abertura do mundo, do outro e da objetividade lógica. Para melhor compreendermos esta perspectiva filosófica, teremos a contribuição de Waldenfels que estenderá o conceito de atitude e tornará, assim, uma ética fenomenológica mais evidente, na qual nossa atitude precisa dar uma resposta ética, ou melhor, não pode não responder, pois a abertura do mundo cria em nós um desafio que nos guiará a uma atitude concreta. Este desafio é gerado por clamores que dialogam com a lei (regra) e a justiça (ética). Este diálogo, em princípio, gera uma estranheza que nos leva a um limiar, criando uma fenda, permitindo um novo processo de constituição. Quando Waldenfels diz que o Ethos começa da planície dos sentidos, quer falar que o que nos afeta depende do corpo próprio que é afetado e que o que nos afeta exprime sentido para nós. Em outras palavras, o que clama a nós como possibilidade de sentido precisa realmente passar pela planície dos sentidos; deverá, portanto ser entendido e vivido pelo corpo próprio. Em Waldenfels, podemos encontrar claramente uma ética responsiva e uma ética dos sentidos, permitindo a construção de uma ética fenomenológica.

Palavras-Chave: Husserl; Merleau-Ponty; Waldenfels; Ética dos sentidos.

\section{BY AESTHETICS LOGOS TO THE OF CULTURAL LOGOS: ETHICAL IMPLICATIONS OF OWN BODY PHENOMENOLOGY}

\begin{abstract}
This paper will raise issues concerning to a phenomenological ethics. For that, we will seek to find subsidies through the passage of the logos of the aesthetic world to the logos of the cultural world in Merleau-Ponty. One common thread will be determined by this philosopher, with the intent to

\footnotetext{
${ }^{1}$ Artigo referente à dissertação de Mestrado apresentada ao Programa de Pós-Graduação em Filosofia, da Universidade Federal de Santa Maria - UFSM, sob orientação do Professor Dr. Marcelo Fabri.

${ }^{2}$ Mestre em Filosofia pelo Programa de Pós-Graduação em Filosofia, da Universidade Federal de Santa Maria.
} 


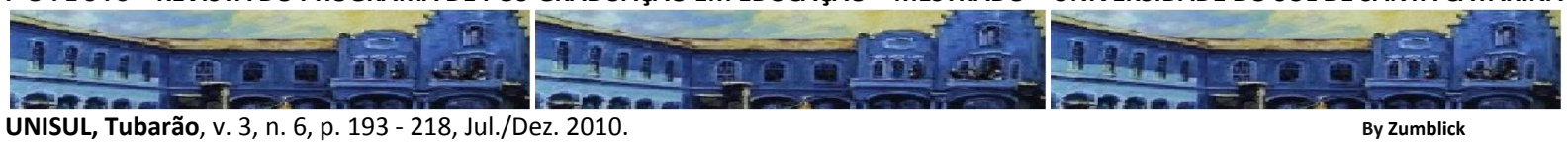

UNISUL, Tubarão, v. 3, n. 6, p. 193 - 218, Jul./Dez. 2010.

By Zumblick

understand the original nature in the life-world. This thread is called original presence which, in turn, can be identified in both the aesthetic logos as in cultural logos. Merleau-Ponty makes a profound

analysis of the studies raised by Husserl, namely a later Husserl, where we find the discovery of a phenomenology of life. Through the discovery of reflexive-body, Merleau-Ponty celebrate the incarnation of the phenomenology of life raised by Husserl. These two philosophers give a strong emphasis facing our attitude toward the opening of the world, the other and the logical objectivity. To better understand this philosophical perspective, we have the contribution of Waldenfels that will extend the concept of attitude and will make, thus, a phenomenological ethic more evident, where this attitude needs to give an answer or rather can not not respond, as the opening of the world create in us a challenge of which I am led to a concrete attitude. This challenge is generated by claims that dialogue with the law (rule) and justice (ethics). This dialogue, in principle, generates a strangeness that drives us to a threshold, creating a gap, allowing a new constitution process. When Waldenfels says that the Ethos begins on the plain of the senses, wants to talk that what affects us depends on the body itself that is affected and that what affects expresses sense for us. In other words, what claims out to us as the possibility of meaning indeed passes through the plain of the senses, must be understood and lived by the own body. In Waldenfels we can find a clear responsive ethics and an ethics of the senses, allowing the construction of a phenomenological ethics.

Keywords: Husserl; Merleau-Ponty; Waldenfels; Ethics of the senses. 


\section{A presença originária.}

Há uma redução de inspiração cartesiana no sentido de uma presença originária em Merleau-Ponty: o sujeito cartesiano resultante das operações da dúvida e do "cogito" é um sujeito concreto, vivencial, não um quadro abstrato ${ }^{3}$. Simultaneamente, esse sujeito é um absoluto, pois tal é o sentido verdadeiro das duas primeiras meditações em Descartes: ele se basta a si mesmo, não tem necessidade de nada para fundar seu ser... a intuição do vivido por si mesmo constitui o modelo de toda evidência originária. Nas Ideen I, Husserl vai refazer o movimento cartesiano a partir do mundo percebido ou mundo natural. Para Husserl, o objeto é constituído pela sedimentação de significações, as quais não são as condições $a$ priori de toda experiência, tomadas, aqui, em sentido kantiano. Ora, o entendimento que estabelece essas condições como fundadoras da experiência em geral é, ele mesmo, já fundado na experiência. Não há anterioridade lógica das categorias nem mesmo das formas pelas quais um sujeito transcendental forneceria objetos; é, ao contrário, como o mostra Erfahrung und Urteil, os juízos e as categorias que eles empregam que supõem uma certeza primeira, aquela que existe o ser, isto é, a crença numa realidade. Husserl a denomina Glaube, fé, crença, para sublinhar que se trata de um "pré-saber". A interpretação que Merleau-Ponty faz do conceito fenomenológico de "presença originária", torna-se o fio condutor para entender seu pensamento. Recitamos, aqui, a esse propósito, uma passagem lapidar do Filósofo e Sua Sombra que Merleau-Ponty extrai de Husserl nas Idéias II: "A totalidade dos objetos que podem estar presentes originariamente e que, para todos os sujeitos comunicantes constituem um domínio de presença originária comum, é a Natureza no sentido primeiro e originário ${ }^{4 \prime}$.

Embora se subsidie em Husserl, Merleau-Ponty interpreta essa tese em um sentido muito próprio. Podemos encontrar esta presença originária na consciência, no corpo e no mundo. Todos estes elementos expressam, de forma recíproca, a sua própria natureza. Desta forma, o ser da consciência não pode ser constituído sem o corpo e sem o mundo, assim como o corpo não pode ser constituído em sua essência sem o mundo e a consciência e, por fim, de igual maneira, o mundo não subsiste em sua essência sem a consciência e o corpo. Escreve Merleau-Ponty: "O mundo é inseparável do sujeito, mas de um sujeito que

\footnotetext{
${ }^{3}$ LYOTARD, 1967, p. 21

${ }^{4}$ MERLEAU-PONTY, 1980(d), p, 252.
} 
não é senão projeto do mundo, mas de um mundo que ele mesmo projeta ${ }^{5 \prime \prime}$. Esta presença originária é a expressão máxima de um logos estético, um logos operante que suscita um clamor, uma intencionalidade operante que sustenta a historicidade de um mundo sensível, de carne. Estamos ancorados neste logos latente, que se abre à nossa consciência, ao nosso corpo e ao próprio mundo que, também, já estão estruturalmente abertos em sua natureza a ele. Se existe uma passagem deste logos estético para um logos cultural é porque a própria passagem traz consigo as marcas desta tradição estética. Desta forma, o logos do mundo cultural não é feito somente de teses, crenças e ideologias. Ele traz consigo uma "tradição estética", reportando um dinamismo operante às marchas da historicidade. Nós nos valemos tanto deste logos cultural como deste logos estético tão somente porque somos abertos a todas as suas possibilidades. Diz Merleau-Ponty: "A cultura jamais nos dá, pois, significações absolutamente transparentes, a gênese do sentido jamais se conclui. ${ }^{6 \prime \prime}$ Podemos constatar que esta presença originária dá-se também no próprio logos cultural como uma cultura operante, aberta ao corpo, a consciência e ao mundo. Assim, esta presença originária além de possuir um logos operante (estético e cultural) também se caracteriza por sua abertura.

Existe uma razão operante que procura um equilíbrio, em uma numa estrutura que primeiramente é abertura, depois equilíbrio e, por fim, possibilidades para novas criações.

Um fenômeno desencadeia outro, não por uma eficácia objetiva, como as que unem os acontecimentos da natureza, mas pelo sentido que ele oferece há uma razão de ser que orienta o fluxo dos fenômenos sem estar explicitamente posta em nenhum deles, um tipo de razão operante ${ }^{7}$.

Esta razão de ser orienta o fluxo dos fenômenos que acarreta uma série de possibilidades de modo que o equilíbrio para o corpo próprio produz uma latência constante, dando margem ao dinamismo da Lebenswelt. Este fluxo de fenômenos traz uma exigência ao ser que participa de tudo que lhe remete à experiência - sua atitude produz criação. "O ser é o que exige de nós criação para que, enquanto criação, dele tenhamos experiência. ${ }^{8 \prime}$. Merleau-Ponty transporta para o ser uma criação que é dada como uma exigência frente à abertura e dinamismo da Lebenswelt. Escreve em Le visible et l'invisible:

\footnotetext{
${ }^{5}$ MERLEAU-PONTY, 1945, p, 491.

${ }^{6}$ MERLEAU-PONTY, 1980(a), p. 143.

${ }^{7}$ MERLEAU-PONTY, 1945, p.61.

${ }^{8}$ MERLEAU-PONTY, 1964, p. 251.
} 
"Trata-se de uma criação que é evocada e engendrada por Lebenswelt como historicidade operante, latente, que a prolonga e dela dá testemunho" ${ }^{9 \prime \prime}$.

No ensaio Filósofo e sua Sombra, Merleau-Ponty introduz um termo novo e decisivo para toda a sua obra futura e reiterando às idéias precedentes que é a ideia do "corpo reflexionante ${ }^{10}$. A consciência finalmente perde seu monopólio de subjetividade transcendental. Ela se encarna no corpo. O corpo reflexionante será o índice de uma radicalização da obra filosófica de Merleau-Ponty numa abordagem que vai além de Husserl e dá margem a novas perspectivas fenomenológicas. Torna-se radical porque rompe com toda uma tradição que separa o corpo da consciência, ou, ainda, que coloca o corpo apenas como condutor dos sentidos e não como reflexionante. Merleau-Ponty transfere para o corpo a reflexividade anteriormente compreendida apenas como faculdade intelectual. Merleau-Ponty passa a atribuir um estatuto ontológico fundante sem precedentes. Isto implica na recusa da concepção anterior de um Cogito reflexivo, e na recusa de uma filosofia da consciência. O que vislumbramos, agora, é uma nova fenomenologia, pois a fenomenologia se torna uma ontologia fenomenológica encarnada. Assim, embora o Husserl da "Krisis", segundo Barbaras, vai dar margem a uma fenomenologia da vida, Merleau-Ponty radicaliza o tema da encarnação nesta fenomenologia, criticamente retomada e retificada. Podemos dizer que há, agora, uma encarnação da fenomenologia da vida em MerleauPonty.

A ideia de uma fenomenologia da vida em Husserl é defendida por Barbaras através dos pressupostos levantados por Husserl em sua obra: "A Crise das Ciências Européias" (Krisis). A tese fundamental envolve o conceito de Lebenswelt, que é o seu horizonte de pesquisa, que, por sua vez, se direciona não a uma intuição direta, mas atende diretamente a uma meditação-como-retorno (Rückbesinnung), ou melhor, pela questão-como-retorno (Rückfrage). Esta questão do retorno é tratada para combater as pretensões das ciências de encontrar nelas mesmas o fundamento, a tal ponto de exigir o fundamento como medida da racionalidade.

Renaud Barbaras ${ }^{11}$ traz um estudo muito importante sobre a questão do mundo-davida que fora trabalhada na Krisis. Segundo Barbaras, a psicologia fenomenológica refere-se

\footnotetext{
${ }^{9}$ Ibid., p. 228.

${ }^{10}$ MERLEAU-PONTY, 1980(d), p. 247

${ }^{11}$ BARBARAS, 2006, p.207.
} 
ao sujeito como parte do mundo, existindo empiricamente, enquanto a fenomenologia transcendental concerne a uma consciência que não é tratada pela destruição do mundo e ela é a possibilidade do mundo como fenômeno. Para Barbaras, Husserl considera a atividade transcendental como vida, sendo que esta descrição emprega palavras e conceitos no domínio da vida (Leben, Erlebnis, lebendige Gegenwart). Assim, Barbaras afirma que a vida escapa da redução fenomenológica, pois aparece novamente no nível transcendental. Portanto, a vida alude a uma distinção entre transcendental e consciência natural. 0 significado de estar no mundo que compreende ambos, o natural e o transcendental, é a principal questão da fenomenologia da vida. Neste sentido, Barbaras defende que fenomenologia é essencialmente fenomenologia da vida. Desta forma, o problema colocado na Krisis relativo ao duplo status do sujeito como sendo ambos, parte do mundo e condição do mundo, é o mesmo que o problema do status da vida.

\section{Sentido ético.}

A partir de $O$ Filósofo e sua Sombra, cremos encontrar subsídios importantes visando uma perspectiva ética. Primeiramente, Merleau-Ponty fará uma análise da própria sombra que se arrasta, sobretudo, na filosofia mais tardia de Husserl. Trata-se de uma questão que Heidegger também teria posto, sob a ideia de impensado. Ao dar-se conta deste tema, Merelau-Ponty mostra que Husserl começa a rever os aspectos da redução como um começo continuado. "Para Husserl os problemas da redução não são uma prévia ou prefácio, mas o começo da investigação; e mais, um começo continuado ${ }^{12 " . ~ A s s i m, ~ e ́ ~ s o m e n t e ~ a t r a v e ́ s ~}$ da reflexão, através de nossos esforços constitutivos que encontraremos o impensável (irrefletido ${ }^{13}$ ) que está à distância. Este irrefletido causará um incômodo para nossas teses habituais, pois ele denunciará justamente a impossibilidade de uma subjetividade absoluta, vindo a redimensionar nossa atitude frente às ciências da natureza, promovendo uma nova reflexão, já que agora, diz Merleau-Ponty, só nos resta um caminho: pensar de novo ${ }^{14 ”}$. Ora, essa atitude já trabalhada por Husserl marcará uma disposição para o pensar filosófico e ético. Antes de tudo, esta atitude envolverá o fio condutor que vai permear toda a obra

\footnotetext{
${ }^{12}$ Ibid., p. 242.

${ }^{13}$ Ibid., p. 243.

${ }^{14}$ Ibid., p. 242.
} 
filosófica de Merleau-Ponty, ou seja, a ideia de um retorno à presença originária enquanto despertar contínuo e operante frente aos próprios atos reflexivos. Por meio dos estudos levantados por Merleau-Ponty, podemos constatar um voltar mais abrangente para a questão da atitude que envolverá uma tríplice posição implícita em sua obra: Primeiramente, a ideia de que o mundo está aberto com todas as suas possibilidades, exigindo de nós uma atitude frente a esta estesiologia originária, ou seja, uma atitude criativa. Um segundo aspecto desta atitude é que ela dirige uma orientação que permite o começo de toda a filosofia, assim, uma atitude orientadora. E, por fim, traz a possibilidade relacional, com o mundo favorecendo um despertar ético sempre, voltado para o mundo sensível como base - uma atitude encarnada. Merleau-Ponty não falará que esta atitude se dará naturalmente, mas dependerá de certa disposição, ou seja, "precisamos colocar nossas teses entre parênteses, para abrir caminho para uma Weltthesis que é antes de todas as teses, uma fé primordial (Urglaube), uma opinião originária (Urdoxa) (...) ${ }^{15 ”}$. Assim, a redução não é um afastamento do mundo, mas índice de um limite do próprio idealismo de Husserl. Ou seja: há algo que resiste a toda a idealização ou redução:

Ao dizer que a redução ultrapassa a atitude natural, Husserl logo acrescenta que esse ultrapassamento conserva "inteiro o mundo da atitude natural". A própria transcendência desse mundo deve conservar um sentido aos olhos da consciência "reduzida", e a imanência transcendental não pode ser sua simples antítese ${ }^{16}$.

Merleau-Ponty aposta na tarefa de um retorno àquilo que as nossas teses não podem suprimir, isto é, o despertar para o mundo-da-vida. Trata-se de compreender que a consciência não é independente em relação ao mundo, enquanto presença originária. Assim, Merleau-Ponty diz que "a atitude transcendental é ainda, e malgrado tudo, natural (natürlich) ${ }^{17 \prime \prime}$. A partir de agora é que podemos melhor compreender como Merleau-Ponty retoma criticamente a fenomenologia - não como um simples aparecer aparente, mas enquanto um novo discurso com dimensões radicalmente ontológicas, nas quais o aparecer torna-se uma presença originária, envolvendo tudo o que também não aparece à nossa visão. Desta forma, a fenomenologia, diz ele, está bem longe de se reduzir num materialismo ou numa filosofia do espírito, pois todo o seu trabalho consiste em revelar uma camada pré-

\footnotetext{
15 Ibid., 243.

${ }^{16}$ Ibid., p. 243.

${ }^{17}$ Ibid., p. 245.
} 
teorética, a partir da qual suas idealizações encontram seus direitos relativos e podem ser ultrapassados.

Ao destacar a consciência e o mundo como níveis de experiências concêntricas, Merleau-Ponty desloca a reflexão para o sensível. A reflexão que sempre fora um atributo exclusivo da consciência se revela, agora, como uma ordem de experiência estesiológica, corporal. Por isso, Merleau-Ponty passa a operar com a noção de corpo reflexionante, para indicar propriamente a relação do eu com as coisas ${ }^{18}$. A partir desse momento, a intencionalidade deixa de ser somente um produto de ligação de um sujeito espiritual. Esta intencionalidade que liga os momentos de minha exploração às coisas funde-se no meu corpo e se torna uma intencionalidade operante, latente na minha carne. Explica MerleauPonty: “A intencionalidade (...) é a transição que, como sujeito carnal, efetuo de uma fase do movimento à outra, transição sempre possível para mim, por princípio, porque sou este animal de percepções e de movimentos que se chama corpo ${ }^{19 "}$.

Do mesmo modo como sinto a experiência de tocar e ser tocado por mim mesmo, posso sentir esta mesma relação quando toco outra pessoa. Há, aí, uma espécie de reflexão prolongada pelo meu corpo como abertura de relação, ou seja, uma sensibilidade do tocar e ser tocado, do olhar e ser olhado. Percebo que meu corpo é excitável e quando aperto a mão de outra pessoa sinto sua presença. Esta presença se irradia no circuito de minha experiência. Manifesta-se, sobretudo, como co-presença, uma co-existência e vivemos nossa intercorporeidade. Ilustra Merleau-Ponty: "Minhas duas mãos, são co-presentes ou coexistem porque são as mãos de um só corpo; o outro aparece por extensão desta copresença. Ele e eu somos os órgãos de uma só intercorporeidade ${ }^{20 "}$. Aqui, Merleau-Ponty dá razão a uma importante noção aprofundada por Husserl, a noção de empatia (Einfühlung). A ideia é a de que há um sentir que se desprende de todo solipsismo para se refletir cinestesicamente no corpo de outrem. Esta relação de empatia caracteriza-se, em sua fase inicial, em sentido estesiológico. Diz Merleau-Ponty: “Assim, o problema da Einfühlung, como o de minha encarnação, desemboca na meditação sobre o sensível, ou, seja se preferir, transporta-se para ele ${ }^{21 "}$. Todo o mundo, com suas coisas entreabertas diante de mim, recebe mais testemunhas além de mim mesmo, ou seja, dentro dos processos

\footnotetext{
${ }^{18}$ Ibid., p.247.

${ }^{19}$ Ibid., p. 248.

${ }^{20}$ Ibid., p. 249.

${ }^{21}$ Ibid., p. 251.
} 
constitutivos, valho-me do outro, de seus testemunhos, das experiências vividas em seu caráter mais geral de "co-existência".

Através destas descobertas oriundas dos estudos levantados por Merleau-Ponty, encontramos raízes sólidas para as futuras pesquisas de Waldenfels que vai explorar essa "Ontologia do Sensível" para trabalhar sua ética fenomenológica. No seu livro "Das Leibliche Selbst" Waldenfels afirma que o Ethos começa na "planície dos Sentidos"22" de tal modo "que o escutar e o olhar, por exemplo, significam, em parte, um meio de olhar e escutar e uma entrada de clamores estranhos que precisam primeiramente se justificar ${ }^{23 \prime \prime}$. Não podemos agir segundo nossa própria vontade, pois precisamos nos justificar, dependemos do outro e de sua sensibilidade para a possibilidade do eu-mesmo. A presença do outro, seu olhar, sua voz, o mover de sua existência, trazem-me uma estranheza fundamental de sua própria historicidade cultural. Waldenfels não propõe uma ética baseada em princípios universais, propõe-nos um Ethos, em que a reabilitação do sensível possa nos mover para a dimensão do outro: "O olhar do outro quebra meu poder ${ }^{24 "}$. Waldenfels ilustra que o logos cultural, seus discursos, costumes, propósitos éticos que visam o bem estar e o respeito ao outro se originam na planície dos sentidos. E podemos concluir que uma reabilitação do sensível, um retorno ao ser bruto, ou seja, o retorno ontológico-fenomenológico dá margem a toda à possibilidade ética.

As coisas estão aí, insistentes. Reivindicam uma presença absoluta, estão de pé a nossa frente, nos envolvendo neste mundo de infinitas possibilidades. Há um desafio do qual fala Waldenfels: a da exigência de uma resposta necessária, enquanto criação operante que envolve um mundo originário, um eu criativo, um outro criativo e um corpo criativo. Precisamos deste espírito bruto, originário que não se prende a nenhuma cultura e exige dele que crie novamente a cultura. Merleau-Ponty conclui o seu ensaio $O$ filósofo e sua Sombra se reportando a esta relação inalienável com o mundo:

As coisas estão ali, não mais somente, como na perspectiva do Renascimento, segundo sua aparência projetiva e segundo a exigência do panorama, mas ao contrário, de pé, insistentes, esfolando o olhar com suas arestas, cada uma reivindicando uma presença absoluta que é incompossível com a das outras e que, no entanto, elas têm todas juntas, em virtude de um sentido de configuração cuja ideia não nos pode ser dada

\footnotetext{
${ }^{22}$ WALDENFELS, 2000, p. 389. "Das Ethos beginnt auf der Ebene der Sinne"

${ }^{23}$ Ibid., pg. 389. "Hinhören um Hinsehen bedeutet immer auch teilweise ein Wegsehen und ein Weghören also ein Eingehen auf fremde Ansprüche (...)Ein Anspruch tritt früher auf als die Frage, ob er berechtigt sei".

${ }^{24}$ Ibid., p. 392. "Der Andere, das fremde Antlitz, der Blick, der mich betrifft, durchbricht mein Können".
} 
pelo "sentido teorético". Os outros também estão ali (eles já estavam ali com a simultaneidade das coisas), não de imediato como espíritos, nem mesmo como "psiquismos", mas tais, por exemplo, como os enfrentamos na cólera ou no amor: fisionomias, gestos, palavras às quais, sem pensamento interposto, as nossas respondem, a ponto de, algumas vezes, voltarmos suas próprias palavras contra eles antes mesmo que nos tenham atingido, tão seguramente, mais seguramente, do que se tivéssemos compreendido - cada um prenhe das outras e confirmadas por eles em seus corpos ${ }^{25}$.

Como podemos incluir a inalienável presença do outro no interior da Lebenswelt? Como estabelecer uma ordem frente a um estranhamento que é dado no patamar das nossas convivências socioculturais e ao mesmo tempo e sem contradição permitirmos o seu dinamismo? Este entrelaçamento entre o próprio e o não próprio, que vivem um estranhamento originário, forma as bases para o desenvolvimento de uma ética fenomenológica em Waldenfels que, por sua vez, envolve uma ética dos sentidos e da resposta.

\section{A questão da ordem em Waldenfels.}

Em seus trabalhos, Waldenfels não procurará um caos no patamar da contingência mundana pelo fato da transcendência ser revestida de uma fenomenologia existencial, mas encontrará uma ordem que não é somente produzida pela consciência, mas pela própria porosidade da vida. Trata-se, para ele, de:

Uma ordem que não é somente constituída pela consciência, (...) requer uma transformação do sujeito - no sentido que o homem não é mais... o guardião do sentido, e a ordem não é mais um significado que obedece as intenções subjetivas ${ }^{26}$.

Esta concepção de ordem retrata perfeitamente aquilo que Wittgenstein propusera quando ilustrava a experiência de uma partida de futebol em que os participantes recebem uma bola e logo começam a jogar diversos jogos, cada qual com determinadas regras. A ordem vai sendo modificada e estabelecida mediante o próprio jogo: "E não se dá também o caso em que jogamos e - fazemos as regras conforme prosseguimos? E também o caso em que as modificamos - conforme prosseguimos ${ }^{27 \prime \prime}$. Em Fenomenologia na França,

\footnotetext{
${ }^{25}$ MERLEAU-PONTY, 1980(d), p.260.

${ }^{26}$ Ibid., pp.548-550.

${ }^{27}$ WITTGENSTEIN, 1979, §83. p. 46.
} 
Waldenfels é influenciado pelo sentido da ordem em Merleau-Ponty (ordem operante), como pelo caráter dinâmico da ordem em Wittgenstein - (fazemos a regra conforme prosseguimos).

Este aspecto da ordem contingente pode ser encontrado em seus estudos de 1985, em sua obra: In den Netzen der Lebenswelt ${ }^{28}$ (Na teia do Mundo-da-Vida). Segundo Dallmayr, ${ }^{29}$ esta ordem é diferente de uma ordem contingente estruturada, mas volta-se para uma ordem aleatória. Assim, Waldenfels irá divergir dos últimos escritos de Husserl, os quais, ao lado de um objetivismo do conhecimento científico, colocam a vida do mundo basicamente como um tipo de significado unificador, numa racionalidade inteligível que abrange perspectivas práticas e cognitivas. Diferentemente de Husserl, Waldenfels irá apontar a diversidade das práticas histórico-culturais como também a porosidade interna das formas-de-vida que não podem mais ser submetidas a uma razão teleológica unificadora. A forma tradicional de aspirações totalizantes conduz o mundo-da-vida a uma desintegração em campos concretos de significação, tornando vulnerável a uma descontínua racionalização. No intento de colocar a necessidade de uma contínua produção e reprodução da ordem, Waldenfels traz à tona as ambiguidades, não querendo com isso defender um irracionalismo ou até mesmo desconsiderar a filosofia da consciência, mas proporcionar o caráter dinâmico que dá margem a um processo criativo da cultura e da história. Em sua proximidade com Merleau-Ponty, Waldenfels define:

É instrutivo ver como - depois de ambiguidades iniciais de um não abandono da filosofia da consciência - a fenomenologia é radicalizada neste caso: o impacto do être brut ou être sauvage empurra a fenomenologia para o mundo da vida através de seus limites ou margens ${ }^{30}$.

Segundo Dallmayr, o que irá acontecer neste limite é uma disjuntura do significado, ou seja, um processo. Na segunda parte de seu livro, Waldenfels levantará aspectos importantes das regras que governam o mundo-da-vida e, também, o status do mundo-davida, levando em conta as suas normas ético-práticas. Revendo a teoria sociológica de Peter Winch (parcialmente inspirado por Wittgenstein), Waldenfels insistirá no caráter abertofechado das regras sociais. O fato que as regras nunca podem ser exaustivamente

\footnotetext{
${ }^{28}$ Cf. WALDENFELS, 1985.

${ }^{29}$ DALLMAYR, 1989, p. 102.

${ }^{30}$ WALDENFELS, 1985, pp. 8-9, 27, 32.
} 
especificadas possibilita algo ainda não regrado e, também, gera a mudança produtiva das regras. Neste sentido:

Existe alguma coisa não regulada ou indomada no visível (...) assim como o invisível e o não dito estão localizados não através do ofuscamento da visão ou do dito, mas no seu interior. ...Em cada trabalho cultural ou processo cultural há um reservatório intacto, não formado ou não desenvolvido - o "sens sauvage" pelo qual não simplesmente espera, não se retém para uma racionalização, mas guarda o processo vivo ${ }^{31}$.

Waldenfels observa as normas ético-práticas (que, para ele, não comportam uma tarefa teleológica), mas abrangem conflitos internos através de um encontro entre o regrado e o não-regrado, entre o normal e o não-normal, o ordinário e o extraordinário. Desta forma, encontramos no mundo uma ordem não-consumada, aberto-fechada, que dá possibilidade para um novo processo de ordem. Assim, no contexto do mundo-da-vida, vivemos um estranhamento originário, no qual a evidência deste estranhamento possibilitará uma recriação ético-cultural no nosso dia-a-dia. Explica Waldenfels:

(...) uma ordem não terminada que deixa espaço para o outro, para o extraordinário (...) as margens: que significam o não-dito e o não-dito dentro do dito, o não-feito e não-feito dentro do feito, o não-regulado e não-familiar no regulado e familiar, o misterioso (estranho) dentro do dia-a$\mathrm{dia}^{32}$.

Em sua outra obra Ordnung im Zwielicht $^{33}$ (Ordem no Crepúsculo), Waldenfels explorará mais a questão da contingência da ordem humana. Ele passa a enfocar a questão do sentido comum e do sentido selvagem, da cultura e da natureza, da razão e do irracionalismo. No primeiro capítulo, Waldenfels vai explorar o caráter da ordem e sua localização na margem ou limiar. De acordo com a tradição filosófica, uma ordem foi sempre vista como uma forma de ordenar aquilo que não está ordenado; esta ordem ou é dada pelo cosmos ou pelo próprio homem. Waldenfels não irá propor um modo de ordem humana ou social preordenada ou imposta categoricamente dentro de um modelo universal, mas uma ordem pautada na estrutura do diálogo ou no intercâmbio de perguntas e respostas. Aqui, Waldenfels usará o termo racionalidade responsiva para designar precisamente aquela ordem que surgirá por intermédio dos recíprocos desafios e provocações causados pelas interações sociais.

\footnotetext{
${ }^{31}$ WALDENFELS, 1985, pp. 8-9.

32 Ibid., pp. 11, 93, 107, 116-117, 175.

${ }^{33}$ Cf. WALDENFELS, 1987.
} 
No segundo capítulo, aparecerá a palavra seletividade para designar as diferentes formas de organizar as relações humanas. Conforme Dallmayr ${ }^{34}$, o ponto de partida da tese é próximo o de Wittgenstein, sendo que as palavras e ações são contextualmente estruturadas. As palavras se inserem nos padrões linguísticos e as ações numa série de eventos narrativos. Recorrendo a psicologia da Gestalt e a fenomenologia social, Waldenfels irá adotar o conceito de campo como uma correlação de elementos estruturados. Assim, ele escreve:

(campo) é uma estrutura interna, um domínio delimitado e flexível da experiência cuja margem e os campos coordenados apontam para diferentes posições internas, e termos cognatos são cenas, estágios, estruturas ou um espaço social ${ }^{35}$.

Dentro de um campo os elementos são organizados seletivamente dando origem a temas dominantes, ou ainda, a uma organização que não obedece tanto a um critério racional universal, mas, antes, relevante. Para Waldenfels, mais do que uma simples função de interesses subjetivos ou preferências, a relevância tem uma origem contextual, no sentido de que um tema pode ganhar proeminência através de um fundo ou por meio de outros temas concorrentes. Em questões de avaliação, Waldenfels justapõe o padrão de importância ou relevância (Wichtigkeit) ao padrão da moral - justiça (regularidade), retidão, (Richtigkeit). Relevância traz a nossa atenção para a contingência, e a retidão, para seu caráter estrito. Esta oposição binária se desenvolve na medida em que nos movemos do comportamento ordinário diário para uma conduta ética e legal. Para Waldenfels, os padrões são uma expressão de seletividade ou ordem seletiva, ou seja, uma ordem restringindo uma abrangência de possibilidades, criando "entre um padrão (dever) e uma habilidade (poder) uma fenda semelhante à assimetria entre o desafio e a resposta ${ }^{36 \prime}$. Para explicar melhor este contraste, Waldenfels analisa a ordem natural do cosmos e a ordem universal da razão que tiveram um papel importante na filosofia tradicional. Na filosofia clássica, o holismo se encontra na base da natureza. Trata-se de uma leitura do mundo como um todo integrado. Já na filosofia moderna, é a generalização ou universalização de regras e normas, ou seja, sua devida aplicação em todos os contextos possíveis e todos os possíveis agentes. Waldenfels irá ressaltar que, embora todas as ordens possuam um lado factual

\footnotetext{
${ }^{34}$ Ibid., p. 105.

${ }^{35}$ WALDENFELS, 1987, p. 54

${ }^{36}$ Ibid., 56.
} 
positivo elas mesmas, são geradas seletivamente. Waldenfels lembra que os estudos sobre a subjetividade moderna levantam, eles mesmos, bifurcações ou ambiguidades entre a contingência e a universalidade, entre o próprio e o estranho, entre a síntese e a antítese, entre o ideal e o prático... Sendo assim, Waldenfels defenderá que a subjetividade moderna não dá conta da tarefa que ela se impôs a si - uma universalização vai chocar-se com seu aspecto contingente. Buscando recursos em Merleau-Ponty como, por exemplo, na noção de corporeidade, Waldenfels conseguirá religar termos como o próprio e o não-próprio sem apagar suas diferenças dentro de uma uniformidade.

Segundo a teoria da ação, um agente persegue um objetivo, empregando, para isso, certos instrumentos ou meios, levando em conta ainda os contextos concretos, oportunidades e necessidades como, também, a estrutura geral das convenções existentes ou normas. Desta forma, as ações podem ser acessadas em termos de sucesso ou eficiência, estando em concordância com as normas que prevalecem. Waldenfels não pretende desvalidar esta teoria (até porque o homem se pauta em parte por ela), mas apresentar outro aspecto da ordem - uma ordem operante e criativa e não apenas já estabelecida. Quer dizer: que dê possibilidades para as inovações e para um constante processo criativo. Em palavras mais simples, tanto Merleau-Ponty como Waldenfels irão trabalhar a partir daquilo que escapa ou é rejeitado, segundo os princípios dos sistemas categoriais universais. Tais realidades receberão importância a partir de uma análise do mundo-da-vida, no qual se trava a luta criativa entre a ordem existente e a emergente. Assim escreve Merleau-Ponty: "Incontestavelmente, há alguma coisa entre a Natureza transcendente, e o em-si do naturalismo, e a imanência do espírito, de seus atos e noemas. É neste entremeio que é preciso tentar avançar ${ }^{37 \prime \prime}$.

Partindo de categorias tradicionais, Waldenfels vai relatar que uma concepção agonal introduz diferentes formas de acessar ações e reações que proporcionam oportunidades disponíveis para serem exploradas frente aos desafios e reações. Geralmente, a mudança agonal não produz uma concordância estável, mas uma contínua negociação e renegociação dos termos de interação, sempre num nível contextualizado concreto. Seguindo MerleauPonty, Waldenfels falará a este respeito de uma inserção agonal corporal ou confrontação (leibleche Auseinandersetzung). ${ }^{38}$

\footnotetext{
${ }^{37}$ MERLEAU-PONTY, 1980(d), p. 246.

${ }^{38}$ WALDENFELS, 1987, pp. 43-46.
} 
Waldenfels procura deixar claro que a alternativa de um moralismo abstrato ou normativismo não é simplesmente um amoralismo ou um niilismo. A partir de uma “perspectiva agonal ${ }^{39 "}$ é importante evitarmos restringir nossa razão a só um aspecto da ordem.

\section{A passagem do logos do mundo estético para o logos cultural e a descoberta da ética}

Um dos aspectos principais para a descoberta da passagem do logos do mundo estético para o logos cultural é justamente o momento reflexionante em que se atém Merleau-Ponty. Este momento, como vimos, é perpassado pelo paradoxo da experiência do corpo. Neste ponto é preciso também levar em conta o quanto Merleau-Ponty se distancia de Husserl. O ponto nevrálgico é o problema da constituição, já que em sua filosofia mais tardia, Husserl via nele alguns "caracteres contraditórios na redução ${ }^{40 "}$. Tanto para Husserl como para Merleau-Ponty, é neste momento de retorno a nós mesmos que há igualmente um "movimento inverso suscitado por ele próprio ${ }^{41 " . ~ S e g u n d o ~ o ~ H u s s e r l ~ t a r d i o, ~ o ~}$ ultrapassamento conserva inteiro o "mundo natural ${ }^{42 "}$ e as "blosse Sachen" (coisas simplesmente coisas) possuem implicações corporais $^{43}$, ou seja, as coisas não são uma natureza em si, mas "nossos arredores" (Unsere Umgebung) ${ }^{44}$. Sabe-se que Husserl nunca se explicou o bastante sobre essas implicações naturais concernentes ao retorno fenomenológico, como, também, não podemos afirmar que ele abandonou sua antiga forma de pensar, mas que estas novas. É sobre este prisma que Merleau-Ponty procura reelaborar a sua própria filosofia. Digamos que a grande novidade radical é a descoberta do "corpo reflexionante $^{45}$ " que expressa, por assim dizer, aquela reabilitação ontológica do sensível ${ }^{46}$, "não há cortes do sujeito em relação ao mundo 47 ", não há, portanto, um homem interior desvinculado do mundo. O que há é o "homem encarnado no mundo ${ }^{48 "}$. Merleau-Ponty atesta a não separação entre o interior e o exterior, o sujeito e o objeto. A redução, tal qual requeria Husserl, é incompleta. Por isso, que para Merleau-Ponty, o único retorno possível

\footnotetext{
${ }^{39}$ Uma perspectiva agonal permite que a razão possa perceber os dois lados de um debate ou de um contexto.

${ }^{40}$ Ibid., p. 234

${ }^{41}$ Ibid., p. 242

${ }^{42}$ Ibid., p. 243

${ }^{43}$ Ibid., p. 245

${ }^{44}$ Ibid., p. 244

${ }^{45}$ Ibid., p. 247

${ }^{46}$ Ibid., p. 247

${ }^{47}$ Ibid., p. 254

${ }^{48}$ Ibid., pp. 250, 253
} 
só pode ser o retorno ao "ser bruto ${ }^{49 ", ~ a ̀ ~ c a r n e ~ e n q u a n t o ~ s e r ~ d e ~ i n d i v i s a ̃ o . ~ S o ́ ~ a s s i m ~ e ́ ~ q u e ~}$ será possível a passagem para a compreensão do logos cultural. Essa passagem é a possibilidade de toda filosofia, de toda investigação, de toda transcendência, é o advento do mundo da cultura e da arte.

Waldenfels aponta-nos para um termo que visa esclarecer essa dimensão do logos estético ou o irrefletido, caracterizando-o como um estranhamento (Fremde). Não há cortes do sujeito e do mundo, observa ele, mas um momento de estranhamento no mundo: "O estranhamento não se encontra simplesmente em algum lugar, é semelhante a estar dormindo e estar acordado, ter saúde e ficar doente, ser jovem ou ser velho... ${ }^{50 "}$. O estranho aqui faz parte do nosso dia-a-dia, de nossa cultura, está entrelaçada em nossa história, não faz parte de uma delimitação (Abgrenzung), mas é a região mesma de um paradoxo, nele trabalha a Filosofia "A natureza do estranhamento existe no cuidado da acessibilidade e da não acessibilidade ${ }^{51 "}$. Podemos, também, encontrar em Merleau-Ponty esse mesmo caráter de estranhamento, na passagem que ele explora a abertura do eu para o que não é eu:

A metafísica é o propósito deliberado de descrever o paradoxo da consciência e da verdade, da troca e da comunicação, o paradoxo onde vive a ciência que o reencontra sob o aspecto do momento em que reconheci que minha experiência, justamente enquanto minha, abre-me para o que não é eu, que sou sensível ao mundo e ao outro, todos os seres que o pensamento objetivo colocava na distância aproximam-se singularmente de $\operatorname{mim}^{52}$.

Este estranhamento, ou paradoxo, intrínseco em toda experiência que nos circunda, revela certo ultrapassamento. A descoberta de uma ontologia do sensível permite, assim, a abertura a um caráter abrangente e fundante da experiência e do pensamento. Como dizia

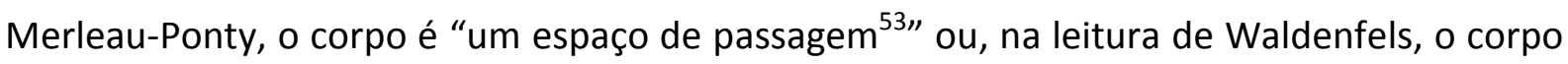
é cultural, tem naturalmente um significado cultural, produz experiência: “O corpo é sempre cultural, no todo que é naturalmente dado, possui uma típica interpretação cultural, organização e esquematização ${ }^{54 \prime}$. Podemos concluir que Merleau-Ponty parte de uma

\footnotetext{
${ }^{49}$ Ibid., p. 251

${ }^{50}$ WALDENFELS, 1997, p.69.

51 Ibid., p. 70.

${ }^{52}$ MERLEAU-PONTY,1980(e), p.188

${ }^{53}$ MERLEAU-PONTY, 1980(d), p.247.

${ }^{54}$ WALDENFELS, 2000, p. 188.
} 
investigação do último Husserl que deixa em aberto aquele paradoxo entre a tarefa de redução e o enigma do mundo-da-vida, trazendo à tona a corpo reflexionante.

Para Waldenfels, quando falamos de vida no mundo, estamos falando de uma “situação aberta" ${ }^{55}$ prenhe de possibilidades. Desta forma se projeta um desafio, no qual sou posto face a face com o estranho, tendo em vista que "não posso deixar de dar uma resposta" ${ }^{56}$. Este estranhamento faz parte do meu dia a dia e "troca (barganha)" 57 experiência com meu ser sensível. Esta "inevitável assimetria" ${ }^{58}$, em que a vida é encarnada no mundo, possibilita um ultrapassamento que não cria cismas, cortes, mas se insere experiência, cultura na linguagem. A descoberta do corpo reflexionante nos abre um precedente ético: estamos imersos no mundo circundante (o mundo de nossos arredores) no qual o outro me interpela eticamente. Diz Waldenfels: "Mas há estas coisas que são introduzidas, irrecusável, esta pessoa amada em sua frente, este homem que existe escravizado ao seu redor... ${ }^{59 \prime \prime}$. Não posso pensar eticamente sem levar em conta a dimensão do outro, a minha sensibilidade e a sensibilidade do outro. Essa troca de experiências, como vimos, torna-se fundamental para a formação do logos cultural em Merleau-Ponty. Sobre este prisma, não poderíamos deixar de focalizar uma ética que parte da fenomenologia. Embora Merleau-Ponty não tenha elaborado uma ética de forma direta, mas implicitamente ${ }^{60}$, encontramos base consistente para pensarmos eticamente, partindo de uma ontologia do ser bruto que abre um campo de presença frente aos nossos arredores. O mundo-da-vida (Lebenswelt) se torna esse logos estético, operante, cuja abertura cria a possibilidade do logos cultural.

\section{A inauguração da ética dos sentidos e da ética da resposta em Waldenfels.}

No seu livro Das Leibliche Selbst Waldenfels diz que "o Ehtos começa na planície dos Sentidos (...) e que o escutar e o olhar, por exemplo, significam, em parte, um meio de olhar

\footnotetext{
${ }^{55}$ Ibid., 2007, tópico 2, n.2.

${ }^{56}$ Ibid., 2007, tópico 3, n.2.

${ }^{57}$ Ibid., 2007, tópico 2, n.2

58 Ibid., 2007, tópico 2, n.2.

59 Ibid., 2007, tópico 3, n.2.

${ }^{60}$ Ibid., 2007, tópico 1, n.2.
} 
e escutar e uma entrada de pretensões estranhas que precisam primeiramente se justificar"61.

Poderíamos dizer que esta é a base fulcral de nosso trabalho, pois o corpo representa aqui o que Merleau-Ponty considera como um espaço de passagem, ou seja, é o campo onde se localizam meus poderes perceptivos, torna-se o vinculum do eu com as coisas. Assim, meu corpo dissipa a separação entre corpo-sujeito, pois ambos fazem parte da mesma base carnal do mundo, vivida pelo corpo próprio. Isto será possível porque meu corpo é reflexionante. Merleau-Ponty expressa esta ideia dizendo:

O conhecimento inteiro e o pensamento objetivo inteiro vivem deste fato inaugural: eu senti: alcancei com esta cor, ou com qualquer outro sensível em questão, uma experiência singular que interrompia de chofre meu olhar, e, no entanto, prometia-lhe uma séria indefinida de experiências... ${ }^{62}$

Neste trecho, notamos não só que o conhecimento depende dessa base sensível polarizada em meu corpo, mas que por meio do meu corpo perceptivo e das coisas que o afetam, vivo uma série indefinida de experiências. Ora, esta interrupção de que fala MerleuPonty caracteriza um estranhamento do qual fala Waldenfels. Estranhamento que vai produzir um desafio. Este desafio só é possível porque existirá uma passagem produzida pelo meu corpo reflexionante. Esta passagem não nos desligará do mundo por meio de nossos processos de redução, mas conservará justamente inteiro o mundo ${ }^{63}$. Aqui, podemos notar que além da ideia de corpo reflexionante eliminar a dicotomia sujeito-corpo, elimina, também, a dicotomia sujeito-objeto, pois nas próprias palavras de Merleau-Ponty: eu estou ancorado neste mundo, participo da mesma carne do mundo. Tratando-se, portanto, de metáforas que atestam aquele caráter de co-presença. Para melhor compreender tais conceitos, precisamos explorar primeiramente o conceito de presença originária. A presença originária é uma ferramenta que nos permite compreender que, embora vivamos num estado de dependência com relação ao mundo, o próprio mundo tem sua tese própria ${ }^{64}$, como minha consciência possui um "eu posso" sujeito e objeto como, também, do corpo e do sujeito, há uma passagem que é possibilidade de toda a cultura. É a presença originária, do eu, do corpo e do mundo que forma a base

\footnotetext{
${ }^{61}$ WALDENFELS, 2000, p. 389.

${ }^{62}$ MERLEAU-PONTY, 1980(d), p. 247.

63 Ibid., p. 243.

${ }^{64}$ Ibid., p. 248.

${ }^{65}$ Ibid., p. 255.
} 
estesiológica do mundo-da-vida. Trata-se, aqui, de uma co-presença, enquanto participação da mesma carne do mundo; o lugar desde onde brota transcendência, em suma, o que permite a passagem do logos do mundo estético para o logos cultural. Nas palavras de Merleau-Ponty:

A ordem do pré-objetivo não é primeira visto que, a bem dizer, só se fixa e começa a existir cumprindo-se na instauração da objetividade lógica. Esta, porém, não é auto-suficiente; limita-se a consagrar o trabalho da camada pré-objetiva, só existindo como finalização do "Logos do mundo estético" e valendo apenas sob seu controle ${ }^{66}$.

Ora, Merleau-Ponty mostra que consciência não é autossuficiente; ela nada seria sem a experiência na qual ela pode ser circunscrita, a saber, a camada pré-objetiva, a presença originária. Deste modo, a própria objetividade lógica prescinde do logos do mundo estético. Merleau-Ponty não quer dizer que os conceitos constituídos são inabaláveis, já que se estabelecem numa base pré-objetiva. Esta base, no entanto, torna os processos constitutivos sempre dinâmicos, pois é impossível darmos conta desta experiência inaugural:

É impossível dar conta dessa experiência inaugural quer fazendo do mundo um fim, quer fazendo dele uma idéia. A solução -se houver - só há de surgir quando interrogamos essa camada sensível, ou, então, quando deixamos cativar por seus enigmas ${ }^{67}$.

A interrogação da camada sensível do ser bruto é a própria expressão da tarefa de "reabilitação ontológica do sensível ${ }^{68 "}$ É através dela, observa Merleau-Ponty, que nossos conhecimentos encontram seu fundamento de direito. Para Merleau-Ponty, a passagem da base pré-objetiva (dimensão do logos originário enquanto logos do mundo estético) para o mundo da cultura e da ciência escapa a toda atitude constitutiva em sentido absoluto. Ela está aberta face às inúmeras possibilidades.

Para Waldenfels, a responsividade descreve-se a partir da abundância de possibilidades que o mundo pode nos apresentar, ou seja, nós respondemos ao mundo, ao outro e nos justificamos quando respondemos. Podemos dizer que Waldenfels vai se preocupar tanto mais com uma efetivação (constante) de uma responsividade ética ${ }^{69}$, ou seja, a atitude filosófica envolverá muito mais uma tomada de decisões (selectividade) do

\footnotetext{
${ }^{66}$ Ibid., p. 253.

${ }^{67}$ Ibid., p. 248.

68 Ibid., p. 247.

${ }^{69}$ DALLMAYR, 1989, p. 474
} 
que uma aspiração teórica. Dentro desta atitude teórica existirá em Waldenfels a perspectiva agonal, no qual a atitude teórica e natural coloca-se como um desafio para a abertura da razão. Ao mesmo tempo, existirá uma atitude prática, a partir a qual precisamos dar uma resposta, precisamos tomar decisões, ou seja, nos movermos até os limites da ordem. Merleau-Ponty, também, trabalhará a questão prática dizendo "que as coisas que percebo não seriam verdadeiramente o ser, se eu não aprendesse que são vistas por outros $^{70 " ~(. . .) ~ " o ~ m u n d o ~ t e m ~ d i r e i t o ~ a ~ m a i s ~ t e s t e m u n h a s ~}{ }^{71 " . ~ E s t a ~ d i m e n s a ̃ o ~ d a ~}$ intersubjetividade vivida através de uma co-presença e do conceito de mundo-da-vida em Husserl e Merleau-Ponty torna impossível a não vivência prática de decisões que precisamos tomar frente às possibilidades que nos são apresentadas. Como mostra Merleau-Ponty: "essa renascença do mundo também é renascença do espírito, redescoberta do espírito bruto que não está aprisionado por nenhuma das culturas e ao qual se pede que crie novamente a cultura ${ }^{72 "}$.

Ora, em nossa avaliação, estes pressupostos envolvem muito mais uma preocupação com os fatores constitutivos do que para uma dimensão ética. Por isto se torna imprescindível a colaboração de Waldenfels para a questão do tema da atitude, pois ele busca luzes tanto em Husserl como em Merleau-Ponty para a inauguração de uma ética responsiva. A atitude se torna, agora, visivelmente imbuída de uma praxidade, pois a perspectiva do estranhamento torna-se incluído no mundo-da-vida. Nesta medida, o caráter de minha atitude necessita do outro, já que não há como ignorar o enigma do outro que me traz um estranhamento primordial. No contexto das ações necessitamos nos justificar dentro dos padrões éticos e legais da ordem. Neste sentido, há "uma entrada de clamores estranhos que precisa primeiramente se justificar" ${ }^{73}$. Quando Waldenfels fala que o Ethos começa na planície dos sentidos, quer justamente explicitar que o que nos afeta depende do corpo próprio enquanto ser afetado, produzindo sentido. Em outras palavras, o que clama (Anspruch) a nós como possibilidade de sentido é permeada pela planície dos sentidos, precisa, portanto, ser compreendida e vivida pelo meu corpo próprio.

O estranhamento não significa que estamos sempre procurando ambiguidades; muito pelo contrário, o estranho marca os limites para que eu me abra a novas

\footnotetext{
${ }^{70}$ MERLEAU-PONTY, 1980(d), p. 248.

${ }^{71}$ Ibid., p. 251.

72 Ibid., p. 260.

${ }^{73}$ WALDENFELS, 2000, p. 389.
} 
possibilidades, um novo processo de ordem, perspectivas éticas e culturais. Quer dizer, não há resposta sem a dimensão ética e não há resposta sem o mover do meu corpo no mundo como diz Waldenfels, e nem criação sem a renascença do mundo e do espírito como diz Merleau-Ponty. Para finalizar, poderíamos dizer que o estranhamento se encontra na presença originária, pois até no meu corpo próprio existe estranhamento trazido pelo clamor que nos levam ao limiar, de tal modo que ecoa de forma primeiramente originária deste ser selvagem, ser bruto, de um de onde (wonach) imediato, prévio a toda constituição. Escreve Waldenfels:

O ethos do sentido significa, que a partir da Sensibilidade do estranho, do outro, somos comissionados ao clamor e que significa, que o corpo próprio como tal subscreve estranhamento. Corporalidade significa por um lado a incompreensibilidade do corpo próprio, que se acha em mim, que se relaciona comigo e que igualmente me escapa, uma estranheza em mim mesmo, que em espelho e eco claramente brilha e ressoa. Esta estranheza me toca de outro lado o longe - perto do outro. A autorreferência descreve ela mesma uma referência ao estranho, que nasce em outro lugar ${ }^{74}$.

Este trecho final da obra de Waldenfels representa o fulcro da dúvida e discussão trazida desde o Husserl mais tardio até Merleau-Ponty e que agora, também, assume um papel fundamental em Waldenfels que é a batalha do próprio e do estranho. Essa batalha, assim cremos,(o próprio e o estranho) não é expressa de forma direta por Husserl e Merleau-Ponty com relação a presença originária, mas muito compreensível indiretamente, representando a essência do originário. Desta forma, a presença originária está em todo lugar, já que ela é tese e antítese, o familiar e o estranho, ciência e religião. É como estar acordado ou dormindo, sujeito e objeto, presença e ausência, o eu e o outro. A presença originária é acordada por clamores ecoados no próprio mundo-da-vida, onde vivo enquanto co-presença, envolto em meus arredores: "A autorreferência descreve ela mesma uma referência ao estranho ${ }^{75 \prime \prime}$. A ética, o logos cultural é feito deste ethos mais originário, dos clamores que vem da história do mundo-da-vida.

O que chamamos de Ethos - a questão de como devemos viver, que clamores nos esperam, como ocorrem violações e responsabilidades - nas áreas da planície da escuta e do olhar, começa na planície dos sentidos. 0 Ethos começa na planície dos sentidos ${ }^{76}$.

\footnotetext{
${ }^{74}$ Ibid., p.393.

${ }^{75}$ Ibid., p. 393.

${ }^{76}$ WALDENFELS, 2000, p. 389.
} 
O estranho, o não-próprio, não deve ser visto como uma ameaça, mas como uma possibilidade, um reaprender a ver. Esta possibilidade, como abertura ao originário, marcará uma reflexão que efetuamos intersubjetivamente, intercorporalmente. Essa discussão sobre a questão do estranho foi iniciada por Husserl", como observa Merleau-Ponty: "Husserl afirma que o não-próprio só se constitui, enquanto tal, a partir de uma analogia com a esfera própria, pois o outro é, ao final das contas, outro eu, uma realidade que só pode ser pensada por analogia àquilo que me pertence" ${ }^{\prime 7}$. Autoconsciência se sente marcada nela mesma como uma autossensação na corporeidade e na afetividade, ou seja, o estranho não é algo ameaçador, mas faz parte do meu dia-a-dia, está em minhas relações com o mundo e com o outro, do eu para o não eu e, como constatamos, vive e projeta este estranhamento em meu próprio corpo. É assim que na Krisis, Husserl fala da cultura europeia; não uma cultura que já tenha alcançado um nível ideal dentro de padrões éticos e legais, mas que o estrangeiro (outra cultura) trará um diálogo fundamental, que colocará nossas teses entre parênteses, não nos afastando do mundo, mas nos lançando para dentro dele, para a esfera própria. Como volta a esclarecer Fabri: "O ponto decisivo é aquele de aprender, graças a relações estabelecidas com outros povos, o exame da própria tradição cultural" 79 . Este estranhamento que nos lança para novas possibilidades, traz um exame de nossa própria cultura É apresentado a nós como presença originária. Há, aqui, um importante alcance pedagógico: o retorno a essa presença originária implica a reaprender a ver o mundo, como afirma Merleau-Ponty no prefácio da Fenomenologia da Percepção. As implicações éticas oriundas no caminho traçado por estes três filósofos (Husserl, Merleau-Ponty e Waldenfels), abrangem características éticas fundamentais para compreendermos a fenomenologia do mundo-da-vida, a presença originária e o estranhamento como base para uma atitude filosófica concernente a uma resposta frente aos clamores que vem até nós como possibilidade de sentido, abarcando uma ação (atitude) concreta, onde uma resposta se torna inevitável. Como Fabri comenta:

O autoestranhamento implica, portanto, um olhar que liberta, na medida do possível, de pré-conceitos e resíduos culturais e tradicionais. Eis porque a fenomenologia não propõe nem a exclusão (colonialismo), nem a inclusão do outro (iluminismo), mas sim a experiência transcendental, isto é, um

\footnotetext{
${ }^{77}$ Cf. HUSSERL, 1932, § 52.

${ }^{78}$ FABRI, 2007, p. 47.

${ }^{79}$ lbid., p. 45.
} 
movimento de vaivém, que consiste na afirmação da subjetividade e no reconhecimento da alteridade ${ }^{80}$.

\section{REFERÊNCIAS BIBLIOGRÁFICAS}

BARBARAS, R. A Phenomenology of life. New York: Cambrigde University Press. 2006.

CARMAN, T. The body in Husserl and Merleau-Ponty. In: Philosophical Topics, vol. 27, no. 2, 1999, pp.205-226.

CHAUÍ, M. Experiência do pensamento: ensaios sobre a obra de Merleau-Ponty. São Paulo: Martins Fontes. 2002.

CROWELL, S. Husserlian phenomenology. In: A companion to phenomenology and existentialism. Edited by Hubert L. Dreyfus, Mark A. Wrathall. Oxford: Blackwell Publishing Ltd. 2006.

FABRI, M. Fenomenologia e cultura: significado crítico e limites da idéia husserliana de Europa. In: Filosofia Unisinos, vol. 8, no. 1, 2007, pp.41-48.

BERGSON, H. Duração e simultaneidade. Trad. Cláudia Berliner. São Paulo: Martins Fontes, 2006.

BONOMI, A. Fenomenologia e estruturalismo. In: Col. Debates. Trad. João Paulo Monteiro, Patrizia Piozzi e Mauro Almeida Alves. São Paulo: Perspectiva. 1973.

DALLMAYR, F. Margins of political discurse. State University of New York Press: Albany, 1989.

DENTZ, R. A. "Corporeidade e subjetividade em Merleau-Ponty". Porto Alegre: Revista Edipucrs, vol. 1, no. 2, 2008, pp.296-307.

GEHRING, P. Can the legal order respond? Ethical Perspectives: jornal of the european ethics network 13, no. 3, 2006, pp.469-496.

HUSSERL, E. Sexta investigação. Trad. Zeljko Loparie e Andréa Maria Altino de Campos Loparie. São Paulo: Editora Nova Cultural, 2000.

Cartesianische meditationen. eine einleitung in die phänomenologie. $V$ meditation. Felix Muiner Verlag: Hamburg. 1932.

. Conferências de Paris.Trad. Artur Morão e António Fidalgo. Lisboa: Edições 70, 1992.

. Die idee der phänomenologie. Husserliana II, La Ha Haye: Martinus Nijhoff. 1950.

\footnotetext{
${ }^{80}$ lbid., p. 46.
} 
. Formale und transzendentale logik, Hamburg: Meiner, 1992.

.Die krisis der europäischen wissenschaften und die transzendentale phänomenologie. eine einleitung in die phänomenologische philosophie. Husserliana: Gesammelte Werke. Band VI. Den Haag, Martinus Nijhoff 1976.

. Idées directrices pour une phénoménologie et une philosophie phénoménologique pures. Livre second, Trad. E. Escoubas. Paris: PUF, 1982.

. L' arche-originaire terre ne se meut pas. recherches fondamentales sur l'origine phénoménologique de la spatialité de la nature. Traduction de l'allemand par D. Franck, D. Pradelle et J. -F. Lavigne. Paris: Minuit, 1989.

Recherches phénoménologiques pour la constituition. Paris: PUF, 1982.

LYOTARD, J. F. A fenomenologia. São Paulo: Difusão Européia do Livro, 1967.

MERLEAU-PONTY, M. A Linguagem indireta e as vozes do silêncio. In: Textos escolhidos. Trad. Marilena Chauí. São Paulo: Abril Cultural, 1980(a).

. Em toda e em nenhuma parte. In: Textos escolhidos. Trad. Marilena Chauí.São Paulo: Abril Cultural, 1980(b).

. Husserl aux limites de la phénomenologie. In: Notes de cours sur L'origine de La géométrie de Husserl, suivi de Recherches sur La phénoménologie de Merleau-Ponty. Paris: PUF, 1998.

. In praise of philosophy, Trans. John Wild, James M. Eide (Evanston: Northwestern University Press, 1963.

. La natura. Milano: Franco Angeli, 1981.

.La prose du monde. Paris: Gallimard, 1969.

. Le visible et l'invisible. Paris: Gallimard, 1964.

. O olho e o espírito. In: Textos escolhidos. Trad. Marilena Chauí. São Paulo: Abril Cultural, 1980(c).

. O filósofo e sua sombra. In: Textos escolhidos. Trad. Marilena Chauí. São Paulo: Abril Cultural, 1980(d).

. O metafísico no homem. In: Textos escolhidos. Trad. Marilena Chauí.São Paulo: Abril Cultural, 1980(e). 
. O primado da percepção e suas conseqüências filosóficas. São Paulo: Papirus, 1990.

. Parcours. Lagrasse:Verder, 2000.

. Phénoménologie de la perception. Paris: Gallimard, 1945.

MÜLLER, M., J. Merleau-Ponty acerca da expressão. Porto Alegre: EDIPUCRS, 2001.

RICOEUR, P. L'école de la phénoménologie. Paris: Vrin, 2004.

SIEWERT, C. Consciousness. In: A companion to phenomenology and existentialism. Edited by Hubert L. Dreyfus, Mark A. Wrathall. Oxford: Blackwell Publishing Ltd. 2006.

SILVA, C., A., F. A carnalidade da reflexão: ipseidade e alteridade em Merleau-Ponty. São Leopoldo (RS): Nova Harmonia, 2009.

. A natureza primordial: Merleau-Ponty e o logos do mundo estético. Cascavel (Pr):

Edunoeste, 2010.

WALDENFELS, B. Antwortgerister. Frankfurt-Main: Shurkamp,1994.

. Bruchlinien der erfahrung. Frankfurt am Main: Suhrkamp, 2002.

. Das leibliche selbst. vorlesungen zur phänomenologie des leibes. Frankfurt am Main: Suhrkamp (=Eds), 2000.

. Das zwischenreich des dialogs; sozial-philosophische untersuchungen im anschluss an Edmund Husserl (Phaenomenologica, vol.41; The Hague: Nijhoff, 1971).

. Der spielraum des verhaltens. Frankfurt-Main: Suhrkamp, 1980.

. Der stachel des fremden. Frankfurt am Main: Suhrkamp,

1990.

. In den netzen der lebenswelt. Frankfurt-Main: Suhrkamp, 1985.

. Innerhalb und ausserhalb der ordnungen. rechtsordnungen in der sicht einer phänomenologie des fremden: Ms. 2002.

n.2, 2007.

La responsività del próprio corpo. In: Kainós, Revista telematica di critica filosófica,

. Ordnung im zwielicht. Frankfurt-Main: Suhrkamp, 1987.

. Phänomenologie des eigenen und des fremden. Berlin: Akda- Verlag, 1997. 
Phänomenologie in frankreich. Frankfurt-Main:Suhrkamp, 1983.

WATSON H. S. Merleau-Ponty's phenomenological itinerary From Body Schema to Situated Knowledge: On How We Are and How We Are Not to "Sing the World". 2007 by Trivium Publications, Amherst, nr,2007.

WAELHENS, A. Phénoménologie et vérité. Louvain: Nauwelaerts 2. ed. 1965.

WITTGENSTEIN, L. Investigações filosóficas. Trad. José Carlos Bruni. São Paulo: Abril Cultural, 1979.

WITTGENSTEIN, L. Philosophische grammatik. Frankfurt: Suhrkamp, 1991. 